\title{
Assessment of diastolic efficiency of blood transit through normal and dysfunctional left ventricles Jonatan Eriksson*1, Petter Dyverfeldt ${ }^{1}$, Tino Ebbers ${ }^{1}$, Ann F Bolger ${ }^{2}$, Jan Engvall ${ }^{1}$ and Carl Johan Carlhäll ${ }^{1}$
}

\begin{abstract}
Address: ${ }^{1}$ Linköping University, Linköping, Sweden and ${ }^{2}$ University of San Francisco, San Francisco, CA, USA
\end{abstract}
* Corresponding author

from 13th Annual SCMR Scientific Sessions

Phoenix, AZ, USA. 21-24 January 2010

Published: 21 January 2010

Journal of Cardiovascular Magnetic Resonance 20 I0, I2(SuppI I):PI86 doi:I0.I I86/I532-429X-I2-SI-PI86

This abstract is available from: http://jcmr-online.com/content/I2/SI/PI86

(c) 2010 Eriksson et al; licensee BioMed Central Ltd.

\section{Objective}

To measure the kinetic energy (KE) loss of blood transit through the left ventricle (LV) during diastole in normal and failing hearts.

\section{Background}

Heart failure represents the final stage of the continuum of cardiovascular diseases. In the failing heart, alterations in LV flow behavior have been recognized and may contribute to the vicious cycle of progressive adverse remodeling. Assessment of the efficiency of blood transiting the LV throughout diastole remains incomplete.

\section{Method}

Seven dilated cardiomyopathy (DCM) patients ( 4 female, aged $52 \pm 14$ years, ejection fraction $43 \pm 5 \%$ [mean \pm $\mathrm{SD}]$ ) and six healthy subjects ( 3 female, aged $58 \pm 4$ years) were studied. $4 \mathrm{D}$ velocity data and morphological b-SSFP images were acquired on a $1.5 \mathrm{~T}$ MRI-scanner (Philips Achieva). The LV endocardium was segmented (http:// segment.heiberg.se) from the short axis images at the times of isovolumetric contraction (IVC) and isovolumetric relaxation (IVR). Pathlines were emitted from the IVC LV blood volume and traced forward and backward in time until IVR, thus including the entire cardiac cycle. The IVR volume was used to determine if and where the traces left the LV. This information was used to automatically separate inflow pathlines into two components [1]: direct flow that enters and leaves the LV within the same cardiac cycle, and retained inflow that does not leave the LV within a single cardiac cycle. By knowing the volume occupied by each trace, its velocity and the density of blood, the change in KE was calculated from the time of the traces' entrance into the LV (by crossing a plane at the mitral annulus) until the time of IVC.

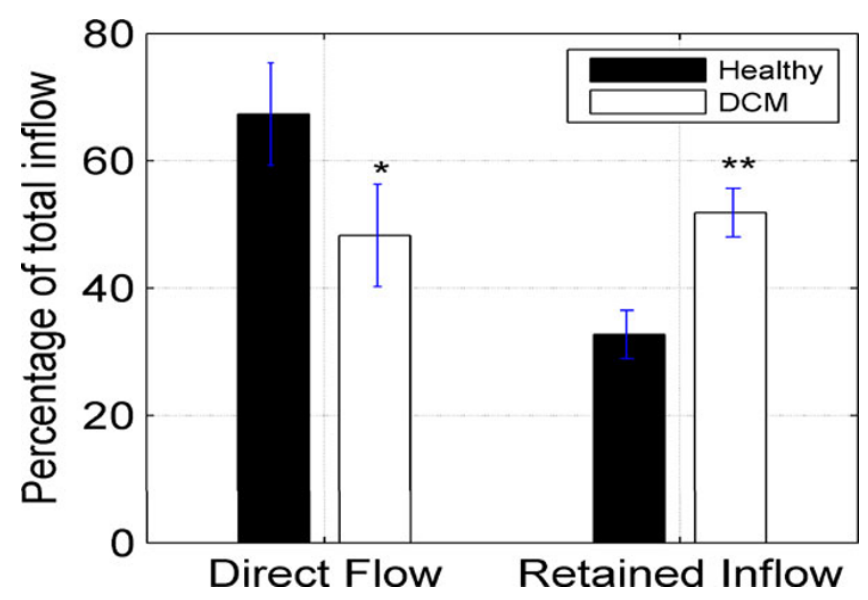

Figure I

Bar graph showing direct flow and retained inflow relative total LV inflow (mean \pm SD) in the six health subjects and seven patients with dialated cardiomyopathy (DCM). *P $<0.00$ I compared to direct flow in healthy subjects, and $* * P<0.001$ compared to retained inflow in health subjects. 


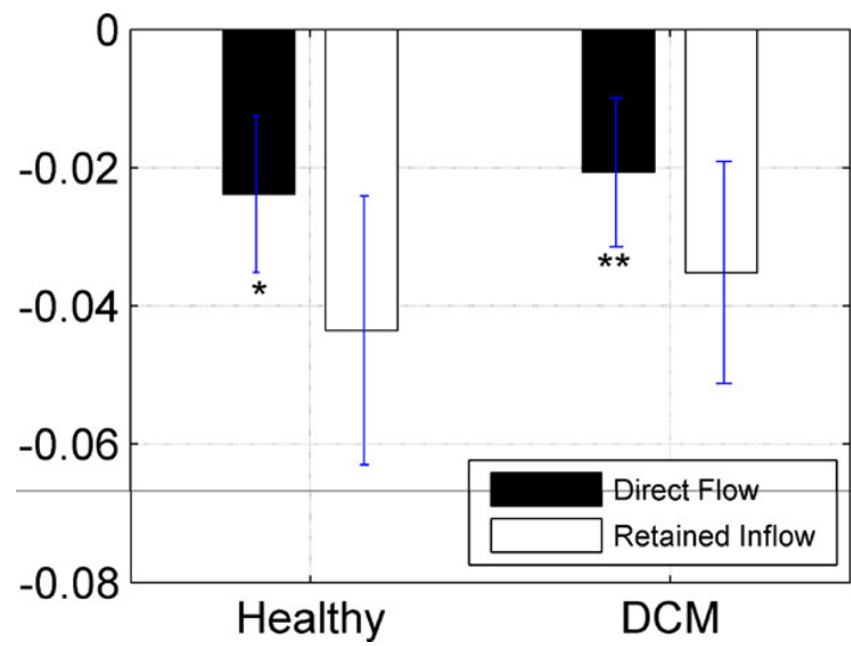

Figure 2

Total change in kinetic energy throughout disastole for direct flow and retained inflow normalized by the volume of each component (mean \pm SD) in the six health subjects and seven patients with dilated cardiomyopath (DCM). *P $<0.01$ compared to retained inflow in health subjects, and $* * P<$ compared to retained inflow in DCM.

\section{Results}

The direct flow/total LV inflow ratio was lower and the retained inflow/total LV inflow ratio was higher in DCM versus healthy subjects ( $48 \pm 4$ vs $67 \pm 8 \%, \mathrm{P}<0.001$, and $52 \pm 4$ vs $33 \pm 8 \%, \mathrm{P}<0.001$, respectively) (Figure 1 ). The kinetic energy loss per $\mathrm{mL}$ blood was higher for retained inflow versus direct flow in both groups $(0.04 \pm 0.02$ vs $0.02 \pm 0.01 \mathrm{~mJ} / \mathrm{mL}, \mathrm{P}<0.01$ ) (Figure 2)

\section{Conclusion}

Although the severity of LV dysfunction was only mild to moderate, the retained inflow represented a significantly larger part of the total inflow in myopathic LVs relative to normal LVs. In both groups, a smaller conservation of KE/ $\mathrm{mL}$ during diastole was observed in the retained inflow compared to the direct flow. Excess KE loss may contribute to the elevated LV filling pressures and progressive adverse remodeling in the failing heart.

\section{References}

I. Eriksson, et al.: ISMRM flow workshop 2009:p47.
Publish with Biomed Central and every scientist can read your work free of charge

"BioMed Central will be the most significant development for disseminating the results of biomedical research in our lifetime. " Sir Paul Nurse, Cancer Research UK

Your research papers will be:

- available free of charge to the entire biomedical community

- peer reviewed and published immediately upon acceptance

- cited in PubMed and archived on PubMed Central

- yours - you keep the copyright

Submit your manuscript here:

http://www.biomedcentral.com/info/publishing_adv.asp 